\title{
Estimation of variances of the effects of incomplete diallels using a matrix approach
}

\author{
Giselle Mariano Lessa de Assis ${ }^{1}$, Ricardo da Fonseca ${ }^{2}$, Cosme Damião Cruz ${ }^{3}$ \\ and José Marques Carneiro Júnior ${ }^{1}$ \\ ${ }^{1}$ Universidade Federal de Viçosa, Departamento de Zootecnia, Viçosa, MG, Brazil. \\ ${ }^{2}$ Universidade Estadual Paulista “Júlio de Mesquita Filho”, Unidade Diferenciada de Dracena, \\ Faculdade de Zootecnia, Dracena, SP, Brazil. \\ ${ }^{3}$ Universidade Federal de Viçosa, Departamento de Biologia Geral, Viçosa, MG, Brazil.
}

\begin{abstract}
A matrix approach is described for assessing the variance of effects in incomplete diallels designs. The method is illustrated by reference to simulated complete and incomplete diallels using different combinations of constraints, average degree of dominance and, for the incomplete diallel, number of hybrids. Our results showed that caution should be taken in working with incomplete diallels under conditions of overdominance because there were changes in the rank of the genotypes when the excluded hybrid had parents with a low frequency of the favorable allele (i.e. the allele which increases expression of a character). The expression described in this paper is a rapid and safe approach to estimate variances and covariances of the effects of contrasts of incomplete diallels.
\end{abstract}

Key words: incomplete diallel, general combining ability, specific combining ability.

Received: March 25, 2003; Accepted: February 16, 2004.

\section{Introduction}

Diallel crosses are an efficient method for the evaluation of the genetic and heterotic potential of parents used in breeding programs. One of the methodologies most widely used to analyze diallel data is that of Griffing (1956) in which the effects of the general combining ability (GCA) and the specific combining ability (SCA) are estimated and then used to find the best parent and hybrid combinations.

In genetic studies using diallel crosses, two analyses of variance (ANOVAR) are performed. The first ANOVAR is directed at the experimental design with the principal objective of testing the significance of the treatments and obtaining the residual mean square which will be used in the next ANOVAR. The second ANOVAR decomposes the sum of squares due to the treatments in CGA and SCA sum of squares using observed means, the variance components and quadratic components also being estimated to provide information on the relative importance of the GCA and SCA. The significance of the effects is verified and any interesting contrasts detected from the estimated variances.

Send correspondence to Giselle Mariano Lessa de Assis. Universidade Federal de Viçosa, Departamento de Zootecnia, Secretaria de Genética e Melhoramento, Av. P.H. Rolphs, 36571-000 Campus Universitário Viçosa, MG, Brazil. E-mail: giselle @ alunos.ufv.br.
This methodology was initially developed to analyze complete diallels, where all the crosses are present for a group of parents but, in practice, it is often not possible to obtain all the possible hybrid combinations because of various factors including differences in fertility, low seedproduction, fertilization problems and adaptation divergence as well as hybrid losses caused by lack of germination, climatic factors, pests and disease, the result being an incomplete diallel cross. In incomplete diallels the parents are represented by a variable number of crosses and the methodology of analysis has to be modified to take into account unbalanced data.

In both complete and incomplete diallels, constraints are often applied to both the parameters and solutions used to solve the equations which calculate the GCA and SCA. The constraints on the solutions do not modify the parametric space and therefore, linear combinations, although of interest, remain non-estimable. Parametric constraints, which are part of the model, are also used in order to enlarge the set of estimable functions and provide more appropriate interpretations of the formulated hypothesis. It is also the case that the solutions arrived at with constraints on the solutions and on the parameters are the same (Cruz and Regazzi, 1997). In incomplete diallels analysis, however, differences in the literature are found regarding the constraints used to estimate the GCA and SCA effects (Machado, 1986 and Cavalcanti et al., 1997). 
With the unbalanced data which characterizes incomplete diallels the estimates of GCA and SCA effects are not obtained as easily as in balanced diallels and a matrix approach is required to produce reliable estimates of the variance and contrasts of the effects (Vencovsky and Barriga, 1992). Although the information provided by tests of effects and contrasts is important, few published papers on incomplete diallels show formulae to calculate these estimators (Keuls and Garretsen, 1997, Garretsen and Keuls, 1978 and Shi et al., 1997).

Our paper describes suitable expressions, based on matrices, for the estimation of the covariance of the GCA and SCA effects of complete and incomplete diallels and the calculation of the variance of the contrasts. We also compare the results obtained using several different constraints and check whether or not the analysis of incomplete diallels generates inadequate results considering some degrees of dominance.

\section{Material and Methods}

\section{Genotypic values}

We considered five genetic populations $(\mathrm{Pi}, \mathrm{i}=1$, $2, \ldots, 5)$ in Hardy-Weinberg equilibrium, the average genotypic values of the hybrids being simulated by setting the favorable allele (i.e. the allele which increases the expression of a character) frequencies between the parents to the values shown in Table 1. Only one locus was assumed with genotypes of AA, Aa and aa and genotypic values of $\mathrm{u}+\mathrm{a}$ for the one homozygote, $\mathrm{u}+\mathrm{d}$ for the heterozygote and $\mathrm{u}$ - a for the other homozygote, where $\mathrm{u}$ is a constant inherent to each observation (Falconer, 1987). The average degree of dominance was also considered in the simulation and it was assumed that $\mathrm{u}=10, \mathrm{a}=10$ and $\mathrm{d}$ had values of 0 , 5,10 and 15 with the average degree of dominance being equal to $0,0.5,1.0$ and 1.5 respectively. The estimated mean for each combination (Table 2) was given by:

$$
\mathrm{Y}_{\mathrm{ij}}=\mathrm{u}+\left(\mathrm{p}_{\mathrm{i}}+\mathrm{p}_{\mathrm{j}}-1\right) \mathrm{a}+\left(\mathrm{p}_{\mathrm{i}}+\mathrm{p}_{\mathrm{j}}-2 \mathrm{p}_{\mathrm{i}} \mathrm{p}_{\mathrm{j}}\right) \mathrm{d}
$$

\section{Complete diallel analysis}

\section{Preliminary ANOVAR}

The preliminary ANOVAR would normally be performed using a specific data set which would result in residual mean square values, but we used simulated means for the hybrids and assumed a mean squared error for the preliminary analysis of variance of 1.00 for all cited cases. If this type of analysis were to be carried out in practice it

Table 1 - Favorable allele frequencies (p) for the five parents ( $\mathrm{Pi}$, where $\mathrm{i}=1,2, \ldots 5)$.

\begin{tabular}{lccccc}
\hline Parent & $\mathrm{P}_{1}$ & $\mathrm{P}_{2}$ & $\mathrm{P}_{3}$ & $\mathrm{P}_{4}$ & $\mathrm{P}_{5}$ \\
\hline $\mathrm{p}$ & 0.1 & 0.3 & 0.5 & 0.7 & 0.9 \\
\hline
\end{tabular}

Table 2 - Hybrids' mean genotypic value, simulated for several average degrees of dominance.

\begin{tabular}{lrccc}
\hline \multirow{2}{*}{ Hybrid } & \multicolumn{4}{c}{ Average degree of dominance } \\
\cline { 2 - 5 } & $\mathrm{d} / \mathrm{a}=0$ & $\mathrm{~d} / \mathrm{a}=0.5$ & $\mathrm{~d} / \mathrm{a}=1.0$ & $\mathrm{~d} / \mathrm{a}=1.5$ \\
\hline $\mathrm{Y}_{12}$ & 4.00 & 5.70 & 7.40 & 9.10 \\
$\mathrm{Y}_{13}$ & 6.00 & 8.50 & 11.00 & 13.50 \\
$\mathrm{Y}_{14}$ & 8.00 & 11.30 & 14.60 & 17.90 \\
$\mathrm{Y}_{15}$ & 10.00 & 14.10 & 18.20 & 22.30 \\
$\mathrm{Y}_{23}$ & 8.00 & 10.50 & 13.00 & 15.50 \\
$\mathrm{Y}_{24}$ & 10.00 & 12.90 & 15.80 & 18.70 \\
$\mathrm{Y}_{25}$ & 12.00 & 15.30 & 18.60 & 21.90 \\
$\mathrm{Y}_{34}$ & 12.00 & 14.50 & 17.00 & 19.50 \\
$\mathrm{Y}_{35}$ & 14.00 & 16.50 & 19.00 & 21.50 \\
$\mathrm{Y}_{45}$ & 16.00 & 17.70 & 19.40 & 21.10 \\
\hline
\end{tabular}

would use on an appropriate experiment design such as a randomized block design with 10 treatments and $\mathrm{r}$ repetitions according to the fixed model:

$$
\mathrm{Y}_{\mathrm{ijk}}=\mathrm{m}+\mathrm{t}_{\mathrm{ij}}+\mathrm{b}_{\mathrm{k}}+\mathrm{e}_{\mathrm{ijk}}
$$

where: $\mathrm{Y}_{\mathrm{ijk}}$ : observation of the ij cross in block $\mathrm{k}$; $\mathrm{m}$ : constant associated with the data; $t_{\mathrm{ij}}$ : effect of the cross $\mathrm{ij} ; \mathrm{b}_{\mathrm{k}}$ : effect of block k; $\mathrm{e}_{\mathrm{ijk}}$ : effect of the random error associated with the ij cross in block $\mathrm{k}$.

\section{Complementary analysis}

For the complementary analysis we used Griffing's method 4, in which the phenotypic values were represented by the mean of the $p(p-1) / 2$ hybrid combinations, where $p$ is the number of parents (Table 3). The fixed statistical model was:

$$
\mathrm{Y}_{\mathrm{ij}}=\mathrm{m}+\mathrm{g}_{\mathrm{i}}+\mathrm{g}_{\mathrm{j}}+\mathrm{s}_{\mathrm{ij}}+\overline{\mathrm{e}}_{\mathrm{ij}}
$$

where: $Y_{\mathrm{ij}}$ : mean value of the hybrid resulting from the cross between parents $\mathrm{i}$ and $\mathrm{j}$; $\mathrm{m}$ : constant associated with the data; $g_{i}, g_{j}$ : effects of the general combining ability of the parents $\mathrm{i}$ and $\mathrm{j}$ respectively; $\mathrm{s}_{\mathrm{ij}}$ : effect of the specific combining ability of the cross between the parents $i$ and $j$; $\overline{\mathrm{e}}_{\mathrm{ij}}$ : random error associated with each observation.

\section{Estimation of parameters}

The least squares method was used to estimate the parameters using the normal equations $X^{\prime} X \hat{\beta}=X^{\prime} y$.

Table 3 - Diallelic table with 5 parents $(\mathrm{Pi}, \mathrm{i}=1,2, \ldots 5)$ and their $\mathrm{F} 1$ hybrids.

\begin{tabular}{cccccc}
\hline & $\mathrm{P}_{1}$ & $\mathrm{P}_{2}$ & $\mathrm{P}_{3}$ & $\mathrm{P}_{4}$ & $\mathrm{P}_{5}$ \\
\hline $\mathrm{P}_{1}$ & - & $\mathrm{Y}_{12}$ & $\mathrm{Y}_{13}$ & $\mathrm{Y}_{14}$ & $\mathrm{Y}_{15}$ \\
$\mathrm{P}_{2}$ & - & - & $\mathrm{Y}_{23}$ & $\mathrm{Y}_{24}$ & $\mathrm{Y}_{25}$ \\
$\mathrm{P}_{3}$ & - & - & - & $\mathrm{Y}_{34}$ & $\mathrm{Y}_{35}$ \\
$\mathrm{P}_{4}$ & - & - & - & - & $\mathrm{Y}_{45}$ \\
$\mathrm{P}_{5}$ & - & - & - & - & - \\
\hline
\end{tabular}


The X matrix was:

$\mathrm{X}=\left[\begin{array}{llllllllllllllll}1 & 1 & 1 & 0 & 0 & 0 & 1 & 0 & 0 & 0 & 0 & 0 & 0 & 0 & 0 & 0 \\ 1 & 1 & 0 & 1 & 0 & 0 & 0 & 1 & 0 & 0 & 0 & 0 & 0 & 0 & 0 & 0 \\ 1 & 1 & 0 & 0 & 1 & 0 & 0 & 0 & 1 & 0 & 0 & 0 & 0 & 0 & 0 & 0 \\ 1 & 1 & 0 & 0 & 0 & 1 & 0 & 0 & 0 & 1 & 0 & 0 & 0 & 0 & 0 & 0 \\ 1 & 0 & 1 & 1 & 0 & 0 & 0 & 0 & 0 & 0 & 1 & 0 & 0 & 0 & 0 & 0 \\ 1 & 0 & 1 & 0 & 1 & 0 & 0 & 0 & 0 & 0 & 0 & 1 & 0 & 0 & 0 & 0 \\ 1 & 0 & 1 & 0 & 0 & 1 & 0 & 0 & 0 & 0 & 0 & 0 & 1 & 0 & 0 & 0 \\ 1 & 0 & 0 & 1 & 1 & 0 & 0 & 0 & 0 & 0 & 0 & 0 & 0 & 1 & 0 & 0 \\ 1 & 0 & 0 & 1 & 0 & 1 & 0 & 0 & 0 & 0 & 0 & 0 & 0 & 0 & 1 & 0 \\ 1 & 0 & 0 & 0 & 1 & 1 & 0 & 0 & 0 & 0 & 0 & 0 & 0 & 0 & 0 & 1\end{array}\right]$

Two distinct sets of constraints were imposed on the $\mathrm{X}$ matrix:

i.

a) Type 1 constraints: $\sum_{\mathrm{i}} \hat{\mathrm{g}}_{\mathrm{i}}=0$ and $\sum_{\mathrm{j}} \hat{\mathrm{s}}_{\mathrm{ij}}=0$, for all

b) Type 2 constraints: $\sum c_{i} \hat{g}_{i}=0$, where $c_{i}=$ number of crosses where the parent $\mathrm{i} i$ is present and $\sum_{\mathrm{j}} \hat{\mathrm{s}}_{\mathrm{ij}}=0$, for
all $\mathrm{i}$.

\section{Variances of effects and contrasts}

The interesting variances of effects and contrasts were calculated by use of the estimators showed in Table 4 (Cruz and Regazzi, 1997). The same variances were also obtained by the matrix approach.

Tests of effects and contrasts

In order to test the effects and contrasts we used the Student's t test:

$$
\mathrm{t}=\frac{\hat{\mathrm{Y}}_{\mathrm{c}}}{\sqrt{\hat{\mathrm{V}}\left(\hat{\mathrm{Y}}_{\mathrm{c}}\right)}}
$$

Table 4 - Variance of effects and contrasts between effects of the general combining ability and specific combining ability.

\begin{tabular}{ll}
\hline Effect or contrast & Variance \\
\hline$\hat{\mathrm{m}}$ & $\left\{\frac{2}{\mathrm{p}(\mathrm{p}-1)}\right\} \sigma_{\mathrm{e}}^{2 *}$ \\
$\hat{\mathrm{g}}_{\mathrm{i}}$ & $\left\{\frac{(\mathrm{p}-1)}{\mathrm{p}(\mathrm{p}-2)}\right\} \sigma_{\mathrm{e}}^{2}$ \\
$\hat{\mathrm{s}}_{\mathrm{ij}}$ & $\left\{\frac{(\mathrm{p}-3)}{(\mathrm{p}-1)}\right\} \sigma_{\mathrm{e}}^{2}$ \\
$\hat{\mathrm{g}}_{\mathrm{i}}-\hat{\mathrm{g}}_{\mathrm{j}}$ & $\left\{\frac{2}{(\mathrm{p}-2)}\right\} \sigma_{\mathrm{e}}^{2}$ \\
$\hat{\mathrm{s}}_{\mathrm{ij}}-\hat{\mathrm{s}}_{\mathrm{ik}}$ & $\left\{\frac{2(\mathrm{p}-3)}{(\mathrm{p}-2)}\right\} \sigma_{\mathrm{e}}^{2}$ \\
$\hat{\mathrm{s}}_{\mathrm{ij}}-\hat{\mathrm{s}}_{\mathrm{km}}$ & $\left\{\frac{2(\mathrm{p}-4)}{(\mathrm{p}-2)}\right\} \sigma_{\mathrm{e}}^{2}$
\end{tabular}

$* \sigma_{\mathrm{e}}^{2}$ is the residual mean square error (MSE) obtained in the preliminary analysis of variance divided by the number of repetitions which produced the means of the hybrids in the diallelic table. Extracted from: (Cruz and Regazzi, 1997). where, $\hat{\mathrm{Y}}_{\mathrm{c}}$ : estimate of the effect or contrast to be tested and $\hat{\mathrm{V}}\left(\hat{\mathrm{Y}}_{\mathrm{c}}\right)$ : estimate of the variance of $\hat{\mathrm{Y}}_{\mathrm{c}}$.

\section{Incomplete diallel analysis}

Three analyses involving incomplete diallels were carried out using the same data set described previously. The incomplete data set was made by excluding hybrid Y15 for one analysis (Case 1), hybrids Y12 and Y13 for another analysis (Case 2) and hybrids Y35 and Y45 for the last analysis (Case 3).

\section{Preliminary ANOVAR}

The primary ANOVAR was conducted using a randomized block design, Case 1 with 9 treatments and r repetitions and Cases 2 and 3 with 8 treatments and $r$ repetitions. The mean square error was assumed to be 1 with $(\mathrm{t}-1)(\mathrm{r}-1)$ degrees of freedom, where $t$ is the number of treatments and $\mathrm{r}$ the number of repetitions (i.e. 3 ).

\section{Complementary analysis and estimation of parameters}

The same methodology and the same two constraints outlined previously were used for all of the three cases.

\section{Variance of effects and contrasts}

The matrix method was used to calculate the covariances of the estimates of the parameters in the model:

$$
\operatorname{Covv}(\hat{\beta})=\left(X^{\prime} X-A^{\prime} A\right)^{-1} X^{\prime} X\left(X^{\prime} X-A^{\prime} A\right)^{-1} \hat{\sigma}_{e}^{2},
$$

where $\hat{\beta}$ is the parametric vector to be estimated with dimension $\left[\frac{\mathrm{p}(\mathrm{p}+1)}{2}+1\right] \times 1 ; \mathrm{X}$ is the incidence matrix with dimension $\left[\frac{\mathrm{p}(\mathrm{p}-1)}{2}\right] \times\left[\frac{\mathrm{p}(\mathrm{p}+1)}{2}+1\right] ; \quad \mathrm{A}$ is the constraints matrix with dimension $\left[\frac{\mathrm{p}(\mathrm{p}-1)}{2}\right] \times\left[\frac{\mathrm{p}(\mathrm{p}+1)}{2}+1\right] ; \hat{\sigma}_{\mathrm{e}}^{2}$ is the residual mean square error divided by the number of repetitions which produced the means of the hybrids included in the diallelic table.

The matrix dimensions shown above refer to the complete diallel model; for the incomplete diallel appropriate changes need to be made to take into account the missing hybrids. For example, matrix A for the complete diallel is:

$\begin{array}{llllllllllllllll}0 & 4 & 4 & 4 & 4 & 4 & 1 & 1 & 1 & 1 & 1 & 1 & 1 & 1 & 1 & 1 \\ 0 & 1 & 1 & 1 & 1 & 1 & 1 & 1 & 1 & 1 & 0 & 0 & 0 & 0 & 0 & 0 \\ 0 & 1 & 1 & 1 & 1 & 1 & 1 & 0 & 0 & 0 & 1 & 1 & 1 & 0 & 0 & 0 \\ 0 & 1 & 1 & 1 & 1 & 1 & 0 & 1 & 0 & 0 & 1 & 0 & 0 & 1 & 1 & 0 \\ 0 & 1 & 1 & 1 & 1 & 1 & 0 & 0 & 1 & 0 & 0 & 1 & 0 & 1 & 0 & 1 \\ 0 & 1 & 1 & 1 & 1 & 1 & 0 & 0 & 0 & 1 & 0 & 0 & 1 & 0 & 1 & 1 \\ 0 & 0 & 0 & 0 & 0 & 0 & 0 & 0 & 0 & 0 & 0 & 0 & 0 & 0 & 0 & 0 \\ 0 & 0 & 0 & 0 & 0 & 0 & 0 & 0 & 0 & 0 & 0 & 0 & 0 & 0 & 0 & 0 \\ 0 & 0 & 0 & 0 & 0 & 0 & 0 & 0 & 0 & 0 & 0 & 0 & 0 & 0 & 0 & 0 \\ 0 & 0 & 0 & 0 & 0 & 0 & 0 & 0 & 0 & 0 & 0 & 0 & 0 & 0 & 0 & 0\end{array}$


while for the incomplete diallel (Case 1), the matrix is:

$\begin{array}{lllllllllllllll}0 & 4 & 4 & 4 & 4 & 4 & 1 & 1 & 1 & 1 & 1 & 1 & 1 & 1 & 1 \\ 0 & 1 & 1 & 1 & 1 & 1 & 1 & 1 & 1 & 0 & 0 & 0 & 0 & 0 & 0 \\ 0 & 1 & 1 & 1 & 1 & 1 & 1 & 0 & 0 & 1 & 1 & 1 & 0 & 0 & 0 \\ 0 & 1 & 1 & 1 & 1 & 1 & 0 & 1 & 0 & 1 & 0 & 0 & 1 & 1 & 0 \\ 0 & 1 & 1 & 1 & 1 & 1 & 0 & 0 & 1 & 0 & 1 & 0 & 1 & 0 & 1 \\ 0 & 1 & 1 & 1 & 1 & 1 & 0 & 0 & 0 & 0 & 0 & 1 & 0 & 1 & 1 \\ 0 & 0 & 0 & 0 & 0 & 0 & 0 & 0 & 0 & 0 & 0 & 0 & 0 & 0 & 0 \\ 0 & 0 & 0 & 0 & 0 & 0 & 0 & 0 & 0 & 0 & 0 & 0 & 0 & 0 & 0 \\ 0 & 0 & 0 & 0 & 0 & 0 & 0 & 0 & 0 & 0 & 0 & 0 & 0 & 0 & 0\end{array}$

Tests of effects and contrasts

To test the effects and contrasts we used the Student's $\mathrm{t}$ test cited previously.

\section{Results and Discussion}

Derivation of an expression to estimate variances and covariances of parameter estimates of incomplete and complete diallels

According to definition, the matrix of covariances of the vector of the estimators of the parameters of the model $(\operatorname{Cov}(\hat{\beta}))$, is given by:

$$
\operatorname{Cov}(\hat{\beta})=E\left[(\hat{\beta}-\beta)(\hat{\beta}-\beta)^{\prime}\right]
$$

$\operatorname{But} \hat{\beta}=\left(X^{\prime} X-A^{\prime} A\right)^{-1} X^{\prime} y$ and $y=X \beta+\varepsilon$, and it follows that:

$$
\begin{aligned}
& \operatorname{Cov}(\hat{\beta})=E\left\{\left[\left(X^{\prime} X-A^{\prime} A\right)^{-1} X^{\prime}(X \beta+\varepsilon)-\beta\right]\right. \\
& \left.\left[\left(X^{\prime} X-A^{\prime} A\right)^{-1} X^{\prime}(X \beta+\varepsilon)-\beta\right]\right\}
\end{aligned}
$$

$\operatorname{Cov}(\hat{\beta})=E\left\{\left[\left(X^{\prime} X-A^{\prime} A\right)^{-1} X^{\prime} X \beta+\left(X^{\prime} X-\right.\right.\right.$

$\left.\left.A^{\prime} A\right)^{-1} X^{\prime} \varepsilon-\beta\right] \times\left[\left(X^{\prime} X-A^{\prime} A\right)^{-1} X^{\prime} X \beta+\right.$

$\left.\left.\left(X^{\prime} X-A^{\prime} A\right)^{-1} X^{\prime} \varepsilon-\beta\right)\right]$

But,

$\left(X^{\prime} X-A^{\prime} A\right)^{-1} X^{\prime} X \beta-\beta=\phi$

Thus:

$\operatorname{Cov}(\hat{\beta})=\mathrm{E}\left[\left(\phi+\left(\mathrm{X}^{\prime} \mathrm{X}-\mathrm{A}^{\prime} \mathrm{A}\right)^{-1} \mathrm{X}^{\prime} \varepsilon\right)\right.$

$\left(\phi+\left(X^{\prime} X-A^{\prime} A\right)^{-1} X^{\prime} \varepsilon\right]$

$\operatorname{Cov}(\hat{\beta})=E\left[\left(X^{\prime} X-A^{\prime} A\right)^{-1} X^{\prime} \varepsilon\right)$

$\left(\left(X^{\prime} X-A^{\prime} A\right)^{-1} X^{\prime} \varepsilon\right]$

Because $\left(\mathrm{X}^{\prime} \mathrm{X}-\mathrm{A}^{\prime} \mathrm{A}\right)^{-1}$ is symmetric, it follows that: $\operatorname{Cov}(\hat{\beta})=E\left[\left(X^{\prime} X-A^{\prime} A\right)^{-1} X^{\prime} \varepsilon \varepsilon^{\prime} X\left(X^{\prime} X-A^{\prime} A\right)^{-1}\right]$

$\operatorname{Cov}(\hat{\beta})=\left(X^{\prime} X-A^{\prime} A\right)^{-1} X^{\prime} E\left(\varepsilon \varepsilon^{\prime}\right) X\left(X^{\prime} X-A^{\prime} A\right)^{-1}$

Because $\mathrm{E}\left(\varepsilon \varepsilon^{\prime}\right)=\sigma_{\mathrm{e}}^{2}$, it follows that:

$\operatorname{Cov}(\hat{\beta})=\left(X^{\prime} X-A^{\prime} A\right)^{-1} X^{\prime} \sigma_{e}^{2} X\left(X^{\prime} X-A^{\prime} A\right)^{-1}$

Finally,

$\operatorname{Cov}(\hat{\beta})=\left(X^{\prime} X-A^{\prime} A\right)^{-1} X^{\prime} X\left(X^{\prime} X-A^{\prime} A\right)^{-1} \sigma_{e}^{2}$

\section{Complete and Incomplete diallel analysis}

Complementary analysis

Table 5 summarizes the complementary ANOVAR of the complete and incomplete diallels. When two hybrids were excluded it was not possible to detect significance in

\begin{tabular}{|c|c|c|c|c|}
\hline \multirow[t]{2}{*}{$\mathrm{VS}$} & \multicolumn{4}{|c|}{ MS } \\
\hline & $\mathrm{d} / \mathrm{a}=0$ & $\mathrm{~d} / \mathrm{a}=0.5$ & $\mathrm{~d} / \mathrm{a}=1.0$ & $\mathrm{~d} / \mathrm{a}=1.5$ \\
\hline & \multicolumn{4}{|c|}{ Complete diallel } \\
\hline GCA & $90.00^{* *}$ & $90.56^{* *}$ & $92.24^{* *}$ & $95.04^{* *}$ \\
\hline \multirow[t]{2}{*}{ SCA } & $0.00^{\mathrm{ns}}$ & $2.48^{\mathrm{ns}}$ & $9.92^{* *}$ & $22.32^{* *}$ \\
\hline & \multicolumn{4}{|c|}{ Incomplete diallel (Case 1) } \\
\hline GCA & $30.00^{* *}$ & $30.02^{* *}$ & $30.07^{* *}$ & $30.16^{* *}$ \\
\hline \multirow[t]{2}{*}{ SCA } & $0.00^{\mathrm{ns}}$ & $0.66^{\mathrm{ns}}$ & $2.63^{\mathrm{ns}}$ & $5.92^{* *}$ \\
\hline & \multicolumn{4}{|c|}{ Incomplete diallel (Case 2) } \\
\hline GCA & $13.88^{* *}$ & $10.44^{* *}$ & $8.42^{* *}$ & $7.83^{* *}$ \\
\hline \multirow[t]{2}{*}{ SCA } & $0.00^{\mathrm{ns}}$ & $0.27^{\mathrm{ns}}$ & $1.08^{\mathrm{ns}}$ & $2.44^{\mathrm{ns}}$ \\
\hline & \multicolumn{4}{|c|}{ Incomplete diallel (Case 3) } \\
\hline GCA & $13.88^{* *}$ & $18.74^{* *}$ & $25.02^{* *}$ & $32.73^{* *}$ \\
\hline SCA & $0.00^{\mathrm{ns}}$ & $0.27^{\mathrm{ns}}$ & $1.08^{\mathrm{ns}}$ & $2.44^{\mathrm{ns}}$ \\
\hline
\end{tabular}
the SCA values for any of the average degrees of domi-

Table 5 - Summary of the complementary analysis of variance of the complete and incomplete diallels for several mean degrees of dominance.

${ }^{\mathrm{ns}}$ No significant difference between treatments by the $\mathrm{F}$ test $(\mathrm{p}=0.01)$. 
nance, which prejudices the biological interpretation of the data because it was not possible to detect dominance in a situation where it was supposed to occur. The effect of GCA was significant $(\mathrm{p}<0.01)$ for every case.

\section{Estimation of parameters}

The estimates of the parameters of the complete and incomplete diallel model for different average degrees of dominance are given in Table 6 , for type 1 constraints and Table 7, for type 2 constraints.

\section{Variances of effects and contrasts}

The variances of the effects and of the contrasts for the complete diallel estimated, using expressions taken from the published literature are shown in Table 8, while those obtained by our matrix approach, are given in Table 9. The variance of the effects can be extracted from the matrix data given in Table 9 and the contrasts calculated, the results being the same as those shown in Table 8. An example of how the variance of the contrast was calculated from the matrix is:

$$
\begin{aligned}
& \hat{\mathrm{V}}\left(\hat{\mathrm{s}}_{\mathrm{ij}}-\hat{\mathrm{s}}_{\mathrm{km}}\right)=\hat{\mathrm{V}}\left(\hat{\mathrm{s}}_{\mathrm{ij}}\right)+\hat{\mathrm{V}}\left(\hat{\mathrm{s}}_{\mathrm{km}}\right)-2 \operatorname{COV}\left(\hat{\mathrm{s}}_{\mathrm{ij}}, \hat{\mathrm{s}}_{\mathrm{km}}\right)= \\
& 0.1667+0.1667-2(0.0556)=0.2222
\end{aligned}
$$

The variance estimates of effects and contrasts of the incomplete diallel obtained by the matrix method for Case 1 are given in Table 10 (for type 1 constraints) and in Table
11 (for type 2 constraints); for Case 2, in Table 12 (for type 1 constraints) and in Table 13 (for type 2 constraints); and for Case 3, in Table 14 (for type 1 constraints) and in Table 15 (for type 2 constraints).

Based on estimates of the mean, the effects of GCA and SCA for different degrees of balance (i.e. balanced and unbalanced data), the average degrees of dominance and the type (1 or 2) of constraints, we can make some conclusions which we will discuss below.

When the diallel is unbalanced, imposing different constraints with regard to the effects of GCA results in different estimates for these parameters, although this is not a major problem because the tests are based on the contrasts of these effects. An interesting contrast is $\mathrm{Y}=\mathrm{g}_{\mathrm{i}}-\mathrm{g}_{\mathrm{j}}$, where the hypothesis test shows that this contrast equals zero. Rejecting this hypothesis means that there is significant difference between the effects of genotype $i$ and genotype $j$ in respect to GCA. The estimates of these contrasts are the same for both type 1 and 2 constraints.

Analyzing the different average degrees of dominance, our results indicate that:

a) In the absence of dominance loss of hybrids does not alter the estimates of the parameters of the model and thus does not alter the order of the genotypes according to the favorable frequencies of the allele when the constraint is type 1 , but when the constraint is type 2 the estimates vary depending on the degree of balance and differ from the

\begin{tabular}{|c|c|c|c|c|c|c|c|c|c|c|c|c|c|c|c|c|}
\hline & $\hat{\mu}$ & $\hat{\mathrm{g}}_{1}$ & $\hat{\mathrm{g}}_{2}$ & $\hat{\mathrm{g}}_{3}$ & $\hat{\mathrm{g}}_{4}$ & $\hat{\mathrm{g}}_{5}$ & $\hat{\mathrm{s}}_{12}$ & $\hat{\mathrm{s}}_{13}$ & $\hat{\mathrm{S}}_{14}$ & $\hat{\mathrm{s}}_{15}$ & $\hat{\mathrm{s}}_{23}$ & $\hat{\mathrm{S}}_{24}$ & $\hat{\mathrm{s}}_{25}$ & $\hat{\mathrm{s}}_{34}$ & $\hat{\mathrm{s}}_{35}$ & $\hat{\mathrm{s}}_{45}$ \\
\hline & \multicolumn{16}{|c|}{$\mathrm{d} / \mathrm{a}=0$} \\
\hline Complete & 10.00 & -4.00 & -2.00 & 0.00 & 2.00 & 4.00 & 0.00 & 0.00 & 0.00 & 0.00 & 0.00 & 0.00 & 0.00 & 0.00 & 0.00 & 0.00 \\
\hline Case 1 & 10.00 & -4.00 & -2.00 & 0.00 & 2.00 & 4.00 & 0.00 & 0.00 & 0.00 & $\mathrm{X}$ & 0.00 & 0.00 & 0.00 & 0.00 & 0.00 & 0.00 \\
\hline Case 2 & 10.00 & -4.00 & -2.00 & 0.00 & 2.00 & 4.00 & $X$ & X & 0.00 & 0.00 & 0.00 & 0.00 & 0.00 & 0.00 & 0.00 & 0.00 \\
\hline \multirow[t]{2}{*}{ Case 3} & 10.00 & -4.00 & -2.00 & 0.00 & 2.00 & 4.00 & 0.00 & 0.00 & 0.00 & 0.00 & 0.00 & 0.00 & 0.00 & 0.00 & $X$ & $\mathrm{X}$ \\
\hline & \multicolumn{16}{|c|}{$\mathrm{d} / \mathrm{a}=0.5$} \\
\hline Complete & 12.70 & -3.73 & -2.13 & -0.27 & 1.87 & 4.27 & -1.13 & -0.20 & 0.47 & 0.87 & 0.20 & 0.47 & 0.47 & 0.20 & -0.20 & -1.13 \\
\hline Case 1 & 12.53 & -4.08 & -1.90 & -0.04 & 2.10 & 3.92 & -0.84 & 0.09 & 0.76 & $\mathrm{X}$ & -0.09 & 0.18 & 0.76 & -0.09 & 0.09 & -0.84 \\
\hline Case 2 & 13.10 & -2.93 & -1.77 & -0.37 & 1.33 & 3.73 & $X$ & $X$ & -0.20 & 0.20 & -0.47 & 0.23 & 0.23 & 0.43 & 0.03 & -0.47 \\
\hline \multirow[t]{2}{*}{ Case 3} & 13.10 & -4.27 & -2.67 & -0.37 & 2.23 & 5.07 & -0.47 & 0.03 & 0.23 & 0.20 & 0.43 & 0.23 & -0.20 & -0.47 & $X$ & $X$ \\
\hline & \multicolumn{16}{|c|}{$\mathrm{d} / \mathrm{a}=1.0$} \\
\hline Complete & 15.40 & -3.47 & -2.27 & -0.53 & 1.73 & 4.53 & -2.27 & -0.40 & 0.93 & 1.73 & 0.40 & 0.93 & 0.93 & 0.40 & -0.40 & -2.27 \\
\hline Case 1 & 15.05 & -4.16 & -1.80 & -0.07 & 2.20 & 3.84 & -1.69 & 0.18 & 1.51 & $\mathrm{X}$ & -0.18 & 0.36 & 1.51 & -0.18 & 0.18 & -1.69 \\
\hline Case 2 & 16.20 & -1.87 & -1.53 & -0.73 & 0.67 & 3.47 & $X$ & $\mathrm{X}$ & -0.40 & 0.40 & -0.93 & 0.47 & 0.47 & 0.87 & 0.07 & -0.93 \\
\hline \multirow[t]{2}{*}{ Case 3} & 16.20 & -4.53 & -3.33 & -0.73 & 2.47 & 6.13 & -0.93 & 0.07 & 0.47 & 0.40 & 0.87 & 0.47 & -0.40 & -0.93 & $X$ & $X$ \\
\hline & \multicolumn{16}{|c|}{$\mathrm{d} / \mathrm{a}=1.5$} \\
\hline Complete & 18.10 & -3.20 & -2.4 & -0.80 & 1.60 & 4.80 & -3.40 & -0.60 & 1.40 & 2.60 & 0.60 & 1.40 & 1.40 & 0.60 & -0.60 & -3.40 \\
\hline Case 1 & 17.58 & -4.24 & -1.71 & -0.11 & 2.29 & 3.76 & -2.53 & 0.27 & 2.27 & $\mathrm{X}$ & -0.27 & 0.53 & 2.27 & -0.27 & 0.27 & -2.53 \\
\hline Case 2 & 19.30 & -0.80 & -1.30 & -1.10 & 0.00 & 3.20 & $\mathrm{X}$ & $\mathrm{X}$ & -0.60 & 0.60 & -1.40 & 0.70 & 0.70 & 1.30 & 0.10 & -1.40 \\
\hline Case 3 & 19.30 & -4.80 & -4.00 & -1.10 & 2.70 & 7.20 & -1.40 & 0.10 & 0.70 & 0.60 & 1.30 & 0.70 & -0.60 & -1.40 & $X$ & $X$ \\
\hline
\end{tabular}
Table 6 - Estimates of the parameters of the complete and incomplete diallel models for Cases 1,2 and 3 (constraints $\sum_{\mathrm{i}} \hat{\mathrm{g}}_{\mathrm{i}}=0$ and $\sum_{\mathrm{j}} \hat{\mathrm{s}}_{\mathrm{ij}}=0$, for all i) and
considering different average degrees of dominance. 
Table 7 - Estimates of the parameters of the complete and incomplete diallel models for Cases 1,2 and 3 (constraints $\sum_{i} c_{i} \hat{g}_{i}=0$ and $\sum_{j} \hat{s}_{i j}=0$, for all i)
and considering different average degrees of dominance.

\begin{tabular}{|c|c|c|c|c|c|c|c|c|c|c|c|c|c|c|c|c|}
\hline & $\hat{\mu}$ & $\hat{\mathrm{g}}_{1}$ & $\hat{\mathrm{g}}_{2}$ & $\hat{\mathrm{g}}_{3}$ & $\hat{\mathrm{g}}_{4}$ & $\hat{\mathrm{g}}_{5}$ & $\hat{\mathrm{s}}_{12}$ & $\hat{\mathrm{S}}_{13}$ & $\hat{\mathrm{S}}_{4}$ & $\hat{\mathrm{S}}_{15}$ & $\hat{\mathrm{s}}_{23}$ & $\hat{\mathrm{s}}_{24}$ & $\hat{\mathrm{S}}_{25}$ & $\hat{\mathrm{s}}_{34}$ & $\hat{\mathrm{s}}_{35}$ & $\hat{\mathrm{s}}_{45}$ \\
\hline & \multicolumn{16}{|c|}{$\mathrm{d} / \mathrm{a}=0$} \\
\hline Complete & 10.00 & -4.00 & -2.00 & 0.00 & 2.00 & 4.00 & 0.00 & 0.00 & 0.00 & 0.00 & 0.00 & 0.00 & 0.00 & 0.00 & 0.00 & 0.00 \\
\hline Case 1 & 10.00 & -4.00 & -2.00 & 0.00 & 2.00 & 4.00 & 0.00 & 0.00 & 0.00 & $\mathrm{X}$ & 0.00 & 0.00 & 0.00 & 0.00 & 0.00 & 0.00 \\
\hline Case 2 & 11.25 & -4.63 & -2.63 & -0.63 & 1.38 & 3.38 & $\mathrm{X}$ & $\mathrm{X}$ & 0.00 & 0.00 & 0.00 & 0.00 & 0.00 & 0.00 & 0.00 & 0.00 \\
\hline \multirow[t]{2}{*}{ Case 3} & 8.75 & -3.38 & -1.38 & 0.63 & 2.63 & 4.63 & 0.00 & 0.00 & 0.00 & 0.00 & 0.00 & 0.00 & 0.00 & 0.00 & $X$ & $X$ \\
\hline & \multicolumn{16}{|c|}{$\mathrm{d} / \mathrm{a}=0.5$} \\
\hline Complete & 12.70 & -3.73 & -2.13 & -0.27 & 1.87 & 4.27 & -1.13 & -0.20 & 0.47 & 0.87 & 0.20 & 0.47 & 0.47 & 0.20 & -0.20 & -1.13 \\
\hline Case 1 & 12.54 & -4.09 & -1.91 & -0.04 & 2.09 & 3.91 & -0.84 & 0.09 & 0.76 & $\mathrm{X}$ & -0.09 & 0.18 & 0.76 & -0.09 & 0.09 & -0.84 \\
\hline Case 2 & 14.10 & -3.43 & -2.27 & -0.87 & 0.83 & 3.23 & $X$ & $X$ & -0.20 & 0.20 & -0.47 & 0.23 & 0.23 & 0.43 & 0.03 & -0.47 \\
\hline \multirow[t]{2}{*}{ Case 3} & 11.60 & -3.52 & -1.92 & 0.38 & 2.98 & 5.82 & -0.47 & 0.03 & 0.23 & 0.20 & 0.43 & 0.23 & -0.20 & -0.47 & $\mathrm{X}$ & $\mathrm{X}$ \\
\hline & \multicolumn{16}{|c|}{$\mathrm{d} / \mathrm{a}=1.0$} \\
\hline Complete & 15.40 & -3.47 & -2.27 & -0.53 & 1.73 & 4.53 & -2.27 & -0.40 & 0.93 & 1.73 & 0.40 & 0.93 & 0.93 & 0.40 & -0.40 & -2.27 \\
\hline Case 1 & 15.09 & -4.18 & -1.82 & -0.09 & 2.18 & 3.82 & -1.69 & 0.18 & 1.51 & $\mathrm{X}$ & -0.18 & 0.36 & 1.51 & -0.18 & 0.18 & -1.69 \\
\hline Case 2 & 16.95 & -2.24 & -1.91 & -1.11 & 0.29 & 3.09 & $\mathrm{X}$ & $\mathrm{X}$ & -0.40 & 0.40 & -0.93 & 0.47 & 0.47 & 0.87 & 0.07 & -0.93 \\
\hline \multirow[t]{2}{*}{ Case 3} & 14.45 & -3.66 & -2.46 & 0.14 & 3.34 & 7.00 & -0.93 & 0.07 & 0.47 & 0.40 & 0.87 & 0.47 & -0.40 & -0.93 & $\mathrm{X}$ & $\mathrm{X}$ \\
\hline & \multicolumn{16}{|c|}{$\mathrm{d} / \mathrm{a}=1.5$} \\
\hline Complete & 18.10 & -3.20 & -2.4 & -0.80 & 1.60 & 4.80 & -3.40 & -0.60 & 1.40 & 2.60 & 0.60 & 1.40 & 1.40 & 0.60 & -0.60 & -3.40 \\
\hline Case 1 & 17.63 & -4.27 & -1.73 & -0.13 & 2.27 & 3.73 & -2.53 & 0.27 & 2.27 & $\mathrm{X}$ & -0.27 & 0.53 & 2.27 & -0.27 & 0.27 & -2.53 \\
\hline Case 2 & 19.80 & -1.05 & -1.55 & -1.35 & -0.25 & 2.95 & $\mathrm{X}$ & $\mathrm{X}$ & -0.60 & 0.60 & -1.40 & 0.70 & 0.70 & 1.30 & 0.10 & -1.40 \\
\hline Case 3 & 17.30 & -3.80 & -3.00 & -0.10 & 3.70 & 8.20 & -1.40 & 0.10 & 0.70 & 0.60 & 1.30 & 0.70 & -0.60 & -1.40 & $\mathrm{X}$ & $\mathrm{X}$ \\
\hline
\end{tabular}

Table 8 - Estimates of the variances of the effects and contrasts from the complete diallel calculated using expressions cited in the literature.

\begin{tabular}{lccccc}
\hline$\hat{\mathrm{V}}(\hat{\mathrm{m}})$ & $\hat{\mathrm{V}}\left(\hat{\mathrm{g}}_{\mathrm{i}}\right)$ & $\hat{\mathrm{V}}\left(\hat{\mathrm{g}}_{\mathrm{i}}-\hat{\mathrm{g}}_{\mathrm{j}}\right)$ & $\hat{\mathrm{V}}\left(\hat{\mathrm{s}}_{\mathrm{ij}}\right)$ & $\hat{\mathrm{V}}\left(\hat{\mathrm{s}}_{\mathrm{ij}}-\hat{\mathrm{s}}_{\mathrm{k}}\right)$ & $\hat{\mathrm{V}}\left(\hat{\mathrm{s}}_{\mathrm{ij}}-\hat{\mathrm{s}}_{\mathrm{km}}\right)$ \\
\hline 0.0333 & 0.0889 & 0.2222 & 0.1667 & 0.4444 & 0.2222 \\
\hline
\end{tabular}

Table 9 - Estimates of the variances and covariances of the effects for a complete diallel model calculated using a matrix approach.

\begin{tabular}{rrrrrrrrrrrrrrrrrr}
\hline 0.0333 & 0.0000 & 0.0000 & 0.0000 & 0.0000 & 0.0000 & 0.0000 & 0.0000 & 0.0000 & 0.0000 & 0.0000 & 0.0000 & 0.0000 & 0.0000 & 0.0000 & 0.0000 \\
0.0000 & 0.0889 & -0.0222 & -0.0222 & -0.0222 & -0.0222 & 0.0000 & 0.0000 & 0.0000 & 0.0000 & 0.0000 & 0.0000 & 0.0000 & 0.0000 & 0.0000 & 0.0000 \\
0.0000 & -0.0222 & 0.0889 & -0.0222 & -0.0222 & -0.0222 & 0.0000 & 0.0000 & 0.0000 & 0.0000 & 0.0000 & 0.0000 & 0.0000 & 0.0000 & 0.0000 & 0.0000 \\
0.0000 & -0.0222 & -0.0222 & 0.0889 & -0.0222 & -0.0222 & 0.0000 & 0.0000 & 0.0000 & 0.0000 & 0.0000 & 0.0000 & 0.0000 & 0.0000 & 0.0000 & 0.0000 \\
0.0000 & -0.0222 & -0.0222 & -0.0222 & 0.0889 & -0.0222 & 0.0000 & 0.0000 & 0.0000 & 0.0000 & 0.0000 & 0.0000 & 0.0000 & 0.0000 & 0.0000 & 0.0000 \\
0.0000 & -0.0222 & -0.0222 & -0.0222 & -0.0222 & 0.0889 & 0.0000 & 0.0000 & 0.0000 & 0.0000 & 0.0000 & 0.0000 & 0.0000 & 0.0000 & 0.0000 & 0.0000 \\
0.0000 & 0.0000 & 0.0000 & 0.0000 & 0.0000 & 0.0000 & 0.1667 & -0.0556 & -0.0556 & -0.0556 & -0.0556 & -0.0556 & -0.0556 & 0.0556 & 0.0556 & 0.0556 \\
0.0000 & 0.0000 & 0.0000 & 0.0000 & 0.0000 & 0.0000 & -0.0556 & 0.1667 & -0.0556 & -0.0556 & -0.0556 & 0.0556 & 0.0556 & -0.0556 & -0.0556 & 0.0556 \\
0.0000 & 0.0000 & 0.0000 & 0.0000 & 0.0000 & 0.0000 & -0.0556 & -0.0556 & 0.1667 & -0.0556 & 0.0556 & -0.0556 & 0.0556 & -0.0556 & 0.0556 & -0.0556 \\
0.0000 & 0.0000 & 0.0000 & 0.0000 & 0.0000 & 0.0000 & -0.0556 & -0.0556 & -0.0556 & 0.1667 & 0.0556 & 0.0556 & -0.0556 & 0.0556 & -0.0556 & -0.0556 \\
0.0000 & 0.0000 & 0.0000 & 0.0000 & 0.0000 & 0.0000 & -0.0556 & -0.0556 & 0.0556 & 0.0556 & 0.1667 & -0.0556 & -0.0556 & -0.0556 & -0.0556 & 0.0556 \\
0.0000 & 0.0000 & 0.0000 & 0.0000 & 0.0000 & 0.0000 & -0.0556 & 0.0556 & -0.0556 & 0.0556 & -0.0556 & 0.1667 & -0.0556 & -0.0556 & 0.0556 & -0.0556 \\
0.0000 & 0.0000 & 0.0000 & 0.0000 & 0.0000 & 0.0000 & -0.0556 & 0.0556 & 0.0556 & -0.0556 & -0.0556 & -0.0556 & 0.1667 & 0.0556 & -0.0556 & -0.0556 \\
0.0000 & 0.0000 & 0.0000 & 0.0000 & 0.0000 & 0.0000 & 0.0556 & -0.0556 & -0.0556 & 0.0556 & -0.0556 & -0.0556 & 0.0556 & 0.1667 & -0.0556 & -0.0556 \\
0.0000 & 0.0000 & 0.0000 & 0.0000 & 0.0000 & 0.0000 & 0.0556 & -0.0556 & 0.0556 & -0.0556 & -0.0556 & 0.0556 & -0.0556 & -0.0556 & 0.1667 & -0.0556 \\
0.0000 & 0.0000 & 0.0000 & 0.0000 & 0.0000 & 0.0000 & 0.0556 & 0.0556 & -0.0556 & -0.0556 & 0.0556 & -0.0556 & -0.0556 & -0.0556 & 0.0556 & 0.1667 \\
\hline
\end{tabular}


Table 10 - Estimates of the variances and covariances of the effects for an incomplete diallel model (Case 1, type 1 constraints) calculated using a matrix approach.

\begin{tabular}{|c|c|c|c|c|c|c|c|c|c|c|c|c|c|c|}
\hline $1 / 25$ & $1 / 75$ & $-2 / 225$ & $-2 / 225$ & $-2 / 225$ & $1 / 75$ & 0 & 0 & 0 & 0 & 0 & 0 & 0 & 0 & 0 \\
\hline $1 / 75$ & $26 / 225$ & $-1 / 25$ & $-1 / 25$ & $-1 / 25$ & $1 / 225$ & 0 & 0 & 0 & 0 & 0 & 0 & 0 & 0 & 0 \\
\hline$-2 / 225$ & $-1 / 25$ & $68 / 675$ & $-7 / 675$ & $-7 / 675$ & $-1 / 25$ & 0 & 0 & 0 & 0 & 0 & 0 & 0 & 0 & 0 \\
\hline$-2 / 225$ & $-1 / 25$ & $-7 / 675$ & $68 / 675$ & $-7 / 675$ & $-1 / 25$ & 0 & 0 & 0 & 0 & 0 & 0 & 0 & 0 & 0 \\
\hline$-2 / 225$ & $-1 / 25$ & $-7 / 675$ & $-7 / 675$ & $68 / 675$ & $-1 / 25$ & 0 & 0 & 0 & 0 & 0 & 0 & 0 & 0 & 0 \\
\hline $1 / 75$ & $1 / 225$ & $-1 / 25$ & $-1 / 25$ & $-1 / 25$ & $26 / 225$ & 0 & 0 & 0 & 0 & 0 & 0 & 0 & 0 & 0 \\
\hline 0 & 0 & 0 & 0 & 0 & 0 & $4 / 27$ & $-2 / 27$ & $-2 / 27$ & $-1 / 27$ & $-1 / 27$ & $-2 / 27$ & $2 / 27$ & $1 / 27$ & $1 / 27$ \\
\hline 0 & 0 & 0 & 0 & 0 & 0 & $-2 / 27$ & $4 / 27$ & $-2 / 27$ & $-1 / 27$ & $2 / 27$ & $1 / 27$ & $-1 / 27$ & $-2 / 27$ & $1 / 27$ \\
\hline 0 & 0 & 0 & 0 & 0 & 0 & $-2 / 27$ & $-2 / 27$ & $4 / 27$ & $2 / 27$ & $-1 / 27$ & $1 / 27$ & $-1 / 27$ & $1 / 27$ & $-2 / 27$ \\
\hline 0 & 0 & 0 & 0 & 0 & 0 & $-1 / 27$ & $-1 / 27$ & $2 / 27$ & $4 / 27$ & $-2 / 27$ & $-1 / 27$ & $-2 / 27$ & $-1 / 27$ & $2 / 27$ \\
\hline 0 & 0 & 0 & 0 & 0 & 0 & $-1 / 27$ & $2 / 27$ & $-1 / 27$ & $-2 / 27$ & $4 / 27$ & $-1 / 27$ & $-2 / 27$ & $2 / 27$ & $-1 / 27$ \\
\hline 0 & 0 & 0 & 0 & 0 & 0 & $-2 / 27$ & $1 / 27$ & $1 / 27$ & $-1 / 27$ & $-1 / 27$ & $4 / 27$ & $2 / 27$ & $-2 / 27$ & $-2 / 27$ \\
\hline 0 & 0 & 0 & 0 & 0 & 0 & $2 / 27$ & $-1 / 27$ & $-1 / 27$ & $-2 / 27$ & $-2 / 27$ & $2 / 27$ & $4 / 27$ & $-1 / 27$ & $-1 / 27$ \\
\hline 0 & 0 & 0 & 0 & 0 & 0 & $1 / 27$ & $-2 / 27$ & $1 / 27$ & $-1 / 27$ & $2 / 27$ & $-2 / 27$ & $-1 / 27$ & $4 / 27$ & $-2 / 27$ \\
\hline 0 & 0 & 0 & 0 & 0 & 0 & $1 / 27$ & $1 / 27$ & $-2 / 27$ & $2 / 27$ & $-1 / 27$ & $-2 / 27$ & $-1 / 27$ & $-2 / 27$ & $4 / 27$ \\
\hline
\end{tabular}

Table 11 - Estimates of the variances and covariances of the effects for an incomplete diallel model (Case 1, type 2 constraints) calculated using a matrix approach.

\begin{tabular}{rrrrrrrrrrrrrrr}
\hline $1 / 27$ & 0 & 0 & 0 & 0 & 0 & 0 & 0 & 0 & 0 & 0 & 0 & 0 & 0 & 0 \\
0 & $7 / 54$ & $-1 / 27$ & $-1 / 27$ & $-1 / 27$ & $1 / 54$ & 0 & 0 & 0 & 0 & 0 & 0 & 0 & 0 & 0 \\
0 & $-1 / 27$ & $5 / 54$ & $-1 / 54$ & $-1 / 54$ & $-1 / 27$ & 0 & 0 & 0 & 0 & 0 & 0 & 0 & 0 & 0 \\
0 & $-1 / 27$ & $-1 / 54$ & $5 / 54$ & $-1 / 54$ & $-1 / 27$ & 0 & 0 & 0 & 0 & 0 & 0 & 0 & 0 & 0 \\
0 & $-1 / 27$ & $-1 / 54$ & $-1 / 54$ & $5 / 54$ & $-1 / 27$ & 0 & 0 & 0 & 0 & 0 & 0 & 0 & 0 & 0 \\
0 & $1 / 54$ & $-1 / 27$ & $-1 / 27$ & $-1 / 27$ & $7 / 54$ & 0 & 0 & 0 & 0 & 0 & 0 & 0 & 0 & 0 \\
0 & 0 & 0 & 0 & 0 & 0 & $4 / 27$ & $-2 / 27$ & $-2 / 27$ & $-1 / 27$ & $-1 / 27$ & $-2 / 27$ & $2 / 27$ & $1 / 27$ & $1 / 27$ \\
0 & 0 & 0 & 0 & 0 & 0 & $-2 / 27$ & $4 / 27$ & $-2 / 27$ & $-1 / 27$ & $2 / 27$ & $1 / 27$ & $-1 / 27$ & $-2 / 27$ & $1 / 27$ \\
0 & 0 & 0 & 0 & 0 & 0 & $-2 / 27$ & $-2 / 27$ & $4 / 27$ & $2 / 27$ & $-1 / 27$ & $1 / 27$ & $-1 / 27$ & $1 / 27$ & $-2 / 27$ \\
0 & 0 & 0 & 0 & 0 & 0 & $-1 / 27$ & $-1 / 27$ & $2 / 27$ & $4 / 27$ & $-2 / 27$ & $-1 / 27$ & $-2 / 27$ & $-1 / 27$ & $2 / 27$ \\
0 & 0 & 0 & 0 & 0 & 0 & $-1 / 27$ & $2 / 27$ & $-1 / 27$ & $-2 / 27$ & $4 / 27$ & $-1 / 27$ & $-2 / 27$ & $2 / 27$ & $-1 / 27$ \\
0 & 0 & 0 & 0 & 0 & 0 & $-2 / 27$ & $1 / 27$ & $1 / 27$ & $-1 / 27$ & $-1 / 27$ & $4 / 27$ & $2 / 27$ & $-2 / 27$ & $-2 / 27$ \\
0 & 0 & 0 & 0 & 0 & 0 & $2 / 27$ & $-1 / 27$ & $-1 / 27$ & $-2 / 27$ & $-2 / 27$ & $2 / 27$ & $4 / 27$ & $-1 / 27$ & $-1 / 27$ \\
0 & 0 & 0 & 0 & 0 & 0 & $1 / 27$ & $-2 / 27$ & $1 / 27$ & $-1 / 27$ & $2 / 27$ & $-2 / 27$ & $-1 / 27$ & $4 / 27$ & $-2 / 27$ \\
0 & 0 & 0 & 0 & 0 & 0 & $1 / 27$ & $1 / 27$ & $-2 / 27$ & $2 / 27$ & $-1 / 27$ & $-2 / 27$ & $-1 / 27$ & $-2 / 27$ & $4 / 27$ \\
\hline
\end{tabular}

Table 12 - Estimates of the variances and covariances of the effects for an incomplete diallel model (Case 2, type 1 constraints) calculated using a matrix approach.

\begin{tabular}{|c|c|c|c|c|c|c|c|c|c|c|c|c|c|}
\hline $4 / 75$ & $1 / 25$ & $1 / 150$ & $1 / 150$ & $-2 / 75$ & $-2 / 75$ & 0 & 0 & 0 & 0 & 0 & 0 & 0 & 0 \\
\hline $1 / 25$ & $38 / 225$ & $-2 / 225$ & $-2 / 225$ & $-17 / 225$ & $-17 / 225$ & 0 & 0 & 0 & 0 & 0 & 0 & 0 & 0 \\
\hline $1 / 150$ & $-2 / 225$ & $107 / 900$ & $-43 / 900$ & $-7 / 225$ & $-7 / 225$ & 0 & 0 & 0 & 0 & 0 & 0 & 0 & 0 \\
\hline $1 / 150$ & $-2 / 225$ & $-43 / 900$ & $107 / 900$ & $-7 / 225$ & $-7 / 225$ & 0 & 0 & 0 & 0 & 0 & 0 & 0 & 0 \\
\hline$-2 / 75$ & $-17 / 225$ & $-7 / 225$ & $-7 / 225$ & $28 / 225$ & $1 / 75$ & 0 & 0 & 0 & 0 & 0 & 0 & 0 & 0 \\
\hline$-2 / 75$ & $-17 / 225$ & $-7 / 225$ & $-7 / 225$ & $1 / 75$ & $28 / 225$ & 0 & 0 & 0 & 0 & 0 & 0 & 0 & 0 \\
\hline 0 & 0 & 0 & 0 & 0 & 0 & $1 / 9$ & $-1 / 9$ & 0 & $-1 / 18$ & $1 / 18$ & $-1 / 18$ & $1 / 18$ & 0 \\
\hline 0 & 0 & 0 & 0 & 0 & 0 & $-1 / 9$ & $1 / 9$ & 0 & $1 / 18$ & $-1 / 18$ & $1 / 18$ & $-1 / 18$ & 0 \\
\hline 0 & 0 & 0 & 0 & 0 & 0 & 0 & 0 & $1 / 9$ & $-1 / 18$ & $-1 / 18$ & $-1 / 18$ & $-1 / 18$ & $1 / 9$ \\
\hline
\end{tabular}


Table 12. (cont.)

\begin{tabular}{|c|c|c|c|c|c|c|c|c|c|c|c|c|c|}
\hline 0 & 0 & 0 & 0 & 0 & 0 & $-1 / 18$ & $1 / 18$ & $-1 / 18$ & $5 / 36$ & $-1 / 12$ & $-1 / 36$ & $1 / 12$ & $-1 / 18$ \\
\hline 0 & 0 & 0 & 0 & 0 & 0 & $1 / 18$ & $-1 / 18$ & $-1 / 18$ & $-1 / 12$ & $5 / 36$ & $1 / 12$ & $-1 / 36$ & $-1 / 18$ \\
\hline 0 & 0 & 0 & 0 & 0 & 0 & $-1 / 18$ & $1 / 18$ & $-1 / 18$ & $-1 / 36$ & $1 / 12$ & $5 / 36$ & $-1 / 12$ & $-1 / 18$ \\
\hline 0 & 0 & 0 & 0 & 0 & 0 & $1 / 18$ & $-1 / 18$ & $-1 / 18$ & $1 / 12$ & $-1 / 36$ & $-1 / 12$ & $5 / 36$ & $-1 / 18$ \\
\hline 0 & 0 & 0 & 0 & 0 & 0 & 0 & 0 & $1 / 9$ & $-1 / 18$ & $-1 / 18$ & $-1 / 18$ & $-1 / 18$ & $1 / 9$ \\
\hline
\end{tabular}

Table 13 - Estimates of the variances and covariances of the effects for an incomplete diallel model (Case 2 , type 2 constraints) calculated using a matrix approach.

\begin{tabular}{|c|c|c|c|c|c|c|c|c|c|c|c|c|c|}
\hline $1 / 24$ & 0 & 0 & 0 & 0 & 0 & 0 & 0 & 0 & 0 & 0 & 0 & 0 & 0 \\
\hline 0 & $61 / 288$ & $5 / 288$ & $5 / 288$ & $-19 / 288$ & $-19 / 288$ & 0 & 0 & 0 & 0 & 0 & 0 & 0 & 0 \\
\hline 0 & $5 / 288$ & $37 / 288$ & $-11 / 288$ & $-11 / 288$ & $-11 / 288$ & 0 & 0 & 0 & 0 & 0 & 0 & 0 & 0 \\
\hline 0 & $5 / 288$ & $-11 / 288$ & $37 / 288$ & $-11 / 288$ & $-11 / 288$ & 0 & 0 & 0 & 0 & 0 & 0 & 0 & 0 \\
\hline 0 & $-19 / 288$ & $-11 / 288$ & $-11 / 288$ & $29 / 288$ & $-1 / 96$ & 0 & 0 & 0 & 0 & 0 & 0 & 0 & 0 \\
\hline 0 & $-19 / 288$ & $-11 / 288$ & $-11 / 288$ & $-1 / 96$ & $29 / 288$ & 0 & 0 & 0 & 0 & 0 & 0 & 0 & 0 \\
\hline 0 & 0 & 0 & 0 & 0 & 0 & $-1 / 9$ & $1 / 9$ & 0 & $1 / 18$ & $-1 / 18$ & $1 / 18$ & $-1 / 18$ & 0 \\
\hline 0 & 0 & 0 & 0 & 0 & 0 & 0 & 0 & $1 / 9$ & $-1 / 18$ & $-1 / 18$ & $-1 / 18$ & $-1 / 18$ & $1 / 9$ \\
\hline 0 & 0 & 0 & 0 & 0 & 0 & $-1 / 18$ & $1 / 18$ & $-1 / 18$ & $5 / 36$ & $-1 / 12$ & $-1 / 36$ & $1 / 12$ & $-1 / 18$ \\
\hline 0 & 0 & 0 & 0 & 0 & 0 & $1 / 18$ & $-1 / 18$ & $-1 / 18$ & $-1 / 12$ & $5 / 36$ & $1 / 12$ & $-1 / 36$ & $-1 / 18$ \\
\hline 0 & 0 & 0 & 0 & 0 & 0 & $-1 / 18$ & $1 / 18$ & $-1 / 18$ & $-1 / 36$ & $1 / 12$ & $5 / 36$ & $-1 / 12$ & $-1 / 18$ \\
\hline 0 & 0 & 0 & 0 & 0 & 0 & 0 & 0 & $1 / 9$ & $-1 / 18$ & $-1 / 18$ & $-1 / 18$ & $-1 / 18$ & $1 / 9$ \\
\hline
\end{tabular}

Table 14 - Estimates of the variances and covariances of the effects for an incomplete diallel model (Case 3, type 1 constraints) calculated using a matrix approach.

\begin{tabular}{|c|c|c|c|c|c|c|c|c|c|c|c|c|c|}
\hline $4 / 75$ & $-2 / 75$ & $-2 / 75$ & $1 / 150$ & $1 / 150$ & $1 / 25$ & 0 & 0 & 0 & 0 & 0 & 0 & 0 & 0 \\
\hline$-2 / 75$ & $28 / 225$ & $1 / 75$ & $-7 / 225$ & $-7 / 225$ & $-17 / 225$ & 0 & 0 & 0 & 0 & 0 & 0 & 0 & 0 \\
\hline$-2 / 75$ & $1 / 75$ & $28 / 225$ & $-7 / 225$ & $-7 / 225$ & $-17 / 225$ & 0 & 0 & 0 & 0 & 0 & 0 & 0 & 0 \\
\hline $1 / 150$ & $-7 / 225$ & $-7 / 225$ & $107 / 900$ & $-43 / 900$ & $-2 / 225$ & 0 & 0 & 0 & 0 & 0 & 0 & 0 & 0 \\
\hline $1 / 150$ & $-7 / 225$ & $-7 / 225$ & $-43 / 900$ & $107 / 900$ & $-2 / 225$ & 0 & 0 & 0 & 0 & 0 & 0 & 0 & 0 \\
\hline $1 / 25$ & $-17 / 225$ & $-17 / 225$ & $-2 / 225$ & $-2 / 225$ & $38 / 225$ & 0 & 0 & 0 & 0 & 0 & 0 & 0 & 0 \\
\hline 0 & 0 & 0 & 0 & 0 & 0 & $-1 / 18$ & $5 / 36$ & $-1 / 36$ & $-1 / 18$ & $-1 / 12$ & $1 / 12$ & $1 / 18$ & $-1 / 18$ \\
\hline 0 & 0 & 0 & 0 & 0 & 0 & $-1 / 18$ & $-1 / 36$ & $5 / 36$ & $-1 / 18$ & $1 / 12$ & $-1 / 12$ & $1 / 18$ & $-1 / 18$ \\
\hline 0 & 0 & 0 & 0 & 0 & 0 & 0 & $-1 / 18$ & $-1 / 18$ & $1 / 9$ & $1 / 18$ & $1 / 18$ & $-1 / 9$ & 0 \\
\hline 0 & 0 & 0 & 0 & 0 & 0 & $-1 / 18$ & $-1 / 12$ & $1 / 12$ & $1 / 18$ & $5 / 36$ & $-1 / 36$ & $-1 / 18$ & $-1 / 18$ \\
\hline 0 & 0 & 0 & 0 & 0 & 0 & $-1 / 18$ & $1 / 12$ & $-1 / 12$ & $1 / 18$ & $-1 / 36$ & $5 / 36$ & $-1 / 18$ & $-1 / 18$ \\
\hline 0 & 0 & 0 & 0 & 0 & 0 & $1 / 9$ & $-1 / 18$ & $-1 / 18$ & 0 & $-1 / 18$ & $-1 / 18$ & 0 & $1 / 9$ \\
\hline
\end{tabular}

estimates of the complete diallel. However, for both constraints the ranking from the best to worst genotypes (i.e. P5, P4, P3, P2, P1) does not change. When only one hybrid (Y15) is lost the estimates are the same as for the complete diallel.

b) For partial dominance and complete dominance the estimates vary according to the degree of balance, although the rank of the genotype continues unaltered according to the allele frequencies.

c) When overdominance occurs, the loss of the Y12 and Y13 hybrids causes alteration in the ranking of the genotypes, which does not occur in the remaining unbalanced designs. In our example, the order of the best to the worst genotype was P5, P4, P1, P3, P2, which indicates that the loss of the hybrid whose parents have a low frequency of the favorable allele can favor these inferior hybrids when overdominance is present. The loss of three hybrids, in which the common parent has a high frequency of the favorable allele, does not produce changes in the rank of the genotype.

There are some interesting points in respect to the variance and covariances matrix. According to the different constraints the estimates of the variance and covariance of the estimates of the SCA effects were the same, which was 
Table 15 - Estimates of the variances and covariances of the effects for an incomplete diallel model (Case 3, type 2 constraints) calculated using a matrix approach.

\begin{tabular}{|c|c|c|c|c|c|c|c|c|c|c|c|c|c|}
\hline $1 / 24$ & 0 & 0 & 0 & 0 & 0 & 0 & 0 & 0 & 0 & 0 & 0 & 0 & 0 \\
\hline 0 & $29 / 288$ & $-1 / 96$ & $-11 / 288$ & $-11 / 288$ & $-19 / 288$ & 0 & 0 & 0 & 0 & 0 & 0 & 0 & 0 \\
\hline 0 & $-1 / 96$ & $29 / 288$ & $-11 / 288$ & $-11 / 288$ & $-19 / 288$ & 0 & 0 & 0 & 0 & 0 & 0 & 0 & 0 \\
\hline 0 & $-11 / 288$ & $-11 / 288$ & $37 / 288$ & $-11 / 288$ & $5 / 288$ & 0 & 0 & 0 & 0 & 0 & 0 & 0 & 0 \\
\hline 0 & $-11 / 288$ & $-11 / 288$ & $-11 / 288$ & $37 / 288$ & $5 / 288$ & 0 & 0 & 0 & 0 & 0 & 0 & 0 & 0 \\
\hline 0 & $-19 / 288$ & $-19 / 288$ & $5 / 288$ & $5 / 288$ & $61 / 288$ & 0 & 0 & 0 & 0 & 0 & 0 & 0 & 0 \\
\hline 0 & 0 & 0 & 0 & 0 & 0 & $1 / 9$ & $-1 / 18$ & $-1 / 18$ & 0 & $-1 / 18$ & $-1 / 18$ & 0 & $1 / 9$ \\
\hline 0 & 0 & 0 & 0 & 0 & 0 & $-1 / 18$ & $5 / 36$ & $-1 / 36$ & $-1 / 18$ & $-1 / 12$ & $1 / 12$ & $1 / 18$ & $-1 / 18$ \\
\hline 0 & 0 & 0 & 0 & 0 & 0 & $-1 / 18$ & $-1 / 36$ & $5 / 36$ & $-1 / 18$ & $1 / 12$ & $-1 / 12$ & $1 / 18$ & $-1 / 18$ \\
\hline 0 & 0 & 0 & 0 & 0 & 0 & 0 & $-1 / 18$ & $-1 / 18$ & $1 / 9$ & $1 / 18$ & $1 / 18$ & $-1 / 9$ & 0 \\
\hline 0 & 0 & 0 & 0 & 0 & 0 & $-1 / 18$ & $-1 / 12$ & $1 / 12$ & $1 / 18$ & $5 / 36$ & $-1 / 36$ & $-1 / 18$ & $-1 / 18$ \\
\hline 0 & 0 & 0 & 0 & 0 & 0 & $-1 / 18$ & $1 / 12$ & $-1 / 12$ & $1 / 18$ & $-1 / 36$ & $5 / 36$ & $-1 / 18$ & $-1 / 18$ \\
\hline 0 & 0 & 0 & 0 & 0 & 0 & 0 & $1 / 18$ & $1 / 18$ & $-1 / 9$ & $-1 / 18$ & $-1 / 18$ & $1 / 9$ & 0 \\
\hline 0 & 0 & 0 & 0 & 0 & 0 & $1 / 9$ & $-1 / 18$ & $-1 / 18$ & 0 & $-1 / 18$ & $-1 / 18$ & 0 & $1 / 9$ \\
\hline
\end{tabular}

not the case for the other parameters in the model. However, when we used data from the two matrices to calculate the variance of the contrast $\left(\mathrm{Y}=\mathrm{g}_{\mathrm{i}}-\mathrm{g}_{\mathrm{j}}\right)$ we obtained the same estimate, i.e., estimates of the variance of the contrast does not change with the constraints. Because of this statistical tests such as the Student's $t$ test will produce the same results using either type I or type II constraints. In other words, when the data is unbalanced the estimate of the covariance between the GCA and SCA effects will always be equal to zero. It is therefore possible to test for the degree to which the data is unbalanced using the different estimates of variance and covariance of the GCA and SCA effects by identifying specific variance and covariance values in the matrix, e.g. to obtain the estimate of the variance of the contrast $Y_{1}=g_{1}-g_{2}$ when hybrid Y15 (Case 1) is excluded we can use:

$$
\begin{aligned}
& \hat{\mathrm{V}}\left(\hat{\mathrm{g}}_{1}-\hat{\mathrm{g}}_{2}\right)=\hat{\mathrm{V}}\left(\hat{\mathrm{g}}_{1}\right)+\hat{\mathrm{V}}\left(\hat{\mathrm{g}}_{2}\right)-2 \operatorname{COOV}\left(\hat{\mathrm{g}}_{1}, \hat{\mathrm{g}}_{2}\right)= \\
& 0.1296+0.0926-2(-0.0370)=0.2963
\end{aligned}
$$

\section{Conclusions}

The fact that different estimates of the GCA effects occur when different constraints are imposed is not important because the estimates of the contrasts usually tested are invariants.

Care should be taken in working with incomplete diallels in which overdominance is present because we found one instance where the rank order of the genotypes changed when the excluded hybrid had parents with a low frequency of the favorable allele.

The expression described in this paper is a rapid and safe approach to estimate variances and covariances of the effects of contrasts of incomplete diallels.

\section{Acknowledgments}

The authors thank the Coordenação de Aperfeiçoamento de Pessoal de Nível Superior (CAPES) for financial support.

\section{References}

Cavalcanti JJV, Pinto CABP, Crisostomo JR and Ferreira DF (1997) Capacidade de combinação do cajueiro (Anacardium occidentale L.) em relação à produção precoce de castanha. Revista Ceres 44:466-472.

Cruz CD and Regazzi AJ (1997) Modelos Biométricos Aplicados ao Melhoramento Genético. 2nd edition. UFV, Viçosa, $390 \mathrm{pp}$.

Garretsen F and Keuls M (1978) A general method for the analysis of genetic variation in complete and incomplete diallels and North Caroline II (NC II) designs. Part II: Procedures and general formulas for the fixed model. Euphytica 27:49-68.

Griffing B (1956) Concept of general and specific combining ability in relation to diallel crossing systems. Austr J Biol Sci 9:463-493.

Keuls M and Garretsen F (1977) A general method for the analysis of genetic variation in complete and incomplete diallels and North Caroline II designs. Part I: Procedures and general formulas for the random model. Euphytica 26:537-551.

Machado TM (1986) Avaliação de cruzamentos intervarietais de milho (Zea mays L.) utilizando o esquema dialélico parcial incompleto. Dissertation, Escola Superior de Agricultura "Luiz de Queiroz", Piracicaba.

Shi CH, Zhu J, Zang RC and Chen GL (1977) Genetic and heterosis analysis for cooking quality traits of Indica rice in different environments. Theor Appl Genet 95:294-300.

Vencovsky R and Barriga P (1992) Genética Biométrica no Fitomelhoramento. Sociedade Brasileira de Genética, Ribeirão Preto, 496 pp. 